\title{
TEORÍA UTÓPICA Y ESPACIO URBANO. EL SUEÑO DE LA CIUDAD IDEAL EN LA NARRATIVA ESPAÑOLA
}

\author{
UTOPIAN THEORY AND URBAN SPACE. THE DREAM OF THE PERFECT
}

CITY IN SPANISH NARRATIVE

Noelia S. García Universidad de Oviedo s.garcianoelia@gmail.com

\begin{abstract}
RESUMEN: Categorizar el concepto de utopía resulta muy complejo al tratarse de un género fronterizo. Establecer un modelo o prototipo utópico es prácticamente imposible ya que cada autor ofrece su propia visión sin adscribirse a ningún tipo concreto. Los elementos sobre los que sustenta el modelo utópico son el espacio y el tiempo. Normalmente suele desarrollarse en una ciudad, representada como un no lugar (Marc Augé). En el caso concreto de la narrativa española, el género utópico ha quedado relegado a la periferia del sistema, focalizándose únicamente sobre textos gestados durante el siglo XIX y de naturaleza política, lo que ha llevado incluso a la negación de la existencia de utopías. El fenómeno utópico español tiene unas características especiales que lo hacen diferenciarse de los modelos canónicos. Esta circunstancia hace que se acerque a otras disciplinas a la vez que se aleja del ámbito estrictamente literario, dando lugar a un género fronterizo e híbrido. El presente artículo pretende realizar una revisión histórico-crítica del género utópico español a través de seis títulos que ilustran las peculiaridades del género en España.
\end{abstract}

PALABRAS CLAVE: Utopía, narrativa española, ciudad, no lugar

ABSTRACT: Categorising the concept of utopia is complex, as this is a genre which crosses borders. Establishing a model or prototype of utopia is practically impossible, as individual authors offer individual visions which do not follow a specific type. The elements that support the utopian model are space and time. This model normally occurs in a city, represented as a no place (Marc Augé). In Spanish narrative, the utopian genre has been pushed to the fringes of the system, only focusing on political texts written during the 19th century. Consequently, the very existence of utopias has been denied. Spanish utopianism has specific characteristics which distinguish it from the canonical models and make it similar to other disciplines, distancing itself from the strictly literary and therefore 
creating a hybrid genre across borders. Through the analysis of six titles which exemplify the peculiarities of the Spanish utopic genre, this article intends to make a historical and critical review of the genre in Spain.

Keywords: Utopia, Spanish Narrative, City, Non-Place

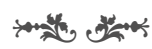

\section{INTRODUCCIÓN}

Categorizar el concepto de utopía resulta muy complejo, puesto que se trata de un género híbrido y fronterizo. Por ello, es necesario acudir a otras disciplinas alejadas del ámbito literario, como la sociología, la filosofía o la política. Tradicionalmente, suele relacionarse con textos que proyectan viajes imaginarios y ciudades ideales, aunque no siempre desde la ficción como se observa en distintas manifestaciones desarrolladas desde la teoría política. En las siguientes páginas, se presentará una revisión histórico-crítica del panorama utópico en relación al desarrollo del género en España y a su especificidad literaria a través de varios títulos significativos al respecto. Por ello, antes de aplicar el concepto a la narrativa española, objeto de estudio en este trabajo, es necesario analizar brevemente la controversia generada en cuanto a la delimitación y definición del género utópico para tratar de comprender las dificultades a las que se ha enfrentado la crítica literaria a la hora de hablar del género utópico en el ámbito español.

\section{TEORÍA UTÓPICA Y ESPACIO URBANO: CONTROVERSIA GENÉRICA}

Para definir qué es una utopía, el primer factor a tener en cuenta es la desestabilización de la jerarquía entre lo real y lo imaginario, ya que a través de ella se muestran las diferentes posibilidades que puede adquirir una sociedad real. Ofrece una nueva visión, cuya función es la de criticar la sociedad y presentar un modelo diferente en el que se hayan superado todos los defectos de la misma. Este hecho lleva a que numerosos estudiosos (Lapouge 1975, Dubois 1968 y Servier 1967) afirmen que es una disciplina inflexible que presenta un proyecto urbano y social ordenado, centralizado y absolutista que impide la entrada de cualquier cambio que rompa la paz y la armonía de la felicidad utópica. Por el contrario, Mumford (2013) entiende que este concepto debe aplicarse a un modelo de sociedad que concibe la ciudad como un todo en el que actúan de forma igualitaria el trabajo, los ciudadanos y el espacio.

En segundo lugar, es necesario hacer hincapié en el hecho de que las utopías tienden a la dispersión, es decir, no poseen un esquema fijo, ni se repiten siempre con las mismas formas, contenidos e imágenes, sino que varían tanto en el fondo como en la forma por su fuerte dependencia con el contexto y la clase social en la que surgen. Partiendo de la sociología del conocimiento, Mannheim (1966) afirma que la clave para entender la utopía radica en la situación del es- 
trato social que las adopta en una época concreta. Sin embargo, una utopía no puede ser una manifestación exclusiva e individual de un autor concreto, puesto que este no tiene la capacidad suficiente para modificar la realidad del momento en el que escribe.

La concepción utópica individual solo puede entenderse porque recoge diversas corrientes de pensamiento que ya estaban presentes y les da forma, es decir, cuando el autor representa la perspectiva de un conjunto social. En este sentido, cabe destacar que las utopías aparecen en conexión con diversos estratos sociales que luchan por un ascenso social. Esta conexión con capas sociales antagónicas es lo que explica la aparición de utopías y distopías, pues su lucha se cristaliza en las diversas formas que adquiere. Mannheim entiende "esas utopías como parte de una constelación total que está transformándose constantemente" (1966: 279). A pesar de la diversidad temática que plantea, sí que se pueden observar preocupaciones y temas que se repiten como la religión, la sociedad o la política. En este sentido, resulta de especial interés el trabajo de Jean Servier quien realizó una recopilación de los rasgos temáticos que, a priori, se repiten y que nos permiten diferenciar una obra utópica de la que no lo es.

De esta forma, Servier entiende que en todas las utopías se realiza una descripción del imaginario urbano de lo que el autor considera una ciudad perfecta que rompe con el antiguo orden social y que otorga poder únicamente a los más aptos para garantizar el bienestar de la comunidad. Esto trae consigo una crítica del antiguo orden social a través de la sátira. El acceso a la ciudad suele realizarse mediante un viaje o un sueño y se destaca la peculiar geografía en la que se sitúa. Suele aparecer en un lugar aislado, normalmente una isla, y se ofrece de ella una ubicación temporal imprecisa. El aislamiento se materializa con la construcción de altas murallas que la rodean, un rasgo tomado de la concepción urbana ideal de Aristóteles. Cabe destacar que las sociedades utópicas sienten nostalgia por el pasado. Su urbanismo recuerda el modelo clásico y suele estar situada junto al mar, un lago o un río, como propuso Platón a través de Calípolis, Atlántida y Magnetes. Por último, la comunidad suele apartar el régimen patriarcal, convirtiendo la ciudad en un matriarcado capaz de satisfacer las necesidades de sus habitantes. En este aspecto, la narrativa española supondrá una excepción, pues la mayor parte de las utopías suelen basarse en modelos patriarcales.

A pesar del intento de creación de un prototipo utópico, el propio Servier afirma que es imposible utilizar esta categorización como modelo, ya que cada autor ofrece su propia visión sin adscribirse a ningún tipo concreto. Esto hace que considere que los conceptos sobre los que se sustenta cualquier modelo utópico sean el espacio y el tiempo. De ahí que entienda las utopías como sinónimo de ucronía, es decir, todas las utopías son atemporales. Si el autor propone una fecha, esta es una falsa precisión que se le proporciona al lector para facilitarle una ubicación temporal, puesto que "la utopía se presenta ante nosotros como la describen los viajeros o soñadores: estática en un eterno presente" (Servier 1969: 235). Esta concepción relaciona el tiempo con las nociones de ser, devenir, imperfección y muerte. Por tanto, es lógico que se pretenda huir del mal y del sufrimiento a través de la inmutabilidad, lo que lleva a que la ciudad se 
represente como un recinto protegido de lo desconocido, de todo mal y aislado físicamente mediante murallas.

En cuanto al espacio, suele desarrollarse en una ciudad, representada como un no lugar, siguiendo la definición de Marc Augé (1993), pues carece de la entidad de las ciudades reales y se presenta como una circunstancia, es decir, viene definida por el tránsito de personajes. El espacio urbano no se personaliza y no aporta una identidad concreta, lo que permite diferenciarla de construcciones no utópicas tan potentes como la Vetusta clariniana. Este es precisamente uno de los problemas que generan los espacios utópicos para la creación de un topos. La ausencia identitaria se debe a que no se profundiza en sus aspectos o componentes y la relación que se establece entre ellos es totalmente artificial. La concepción de la ciudad utópica como un no lugar puede observarse en las manifestaciones más actuales de la narrativa española a través de la imagen de la ciudad de vacaciones, entendida como un paraíso urbano en el que los turistas se mueven constantemente buscando un espacio que les permita recrearse en actividades de ocio, por ejemplo, en El dorado de Robert Juan-Cantavella (2008).

Al margen de los conceptos de tiempo y espacio que se repiten en la mayor parte de las utopías, acercarse a su definición resulta de enorme complejidad. Como sostiene Facuse (2010), es un género fronterizo que entrecruza constantemente la literatura con otras disciplinas como la política o la filosofía y debe entenderse como una manifestación de ruptura con el orden establecido. Profundizar en esta afirmación nos lleva a hablar del concepto de distopía, al relacionar la utopía con el orden y la planificación. Si aplicamos el concepto a las ciudades ideales de Platón y Aristóteles, el orden y la planificación hacen derivar la noción hacia el totalitarismo y el absolutismo. Sin embargo, la utopía ha de entenderse como un todo urbano en el que prima la igualdad y supone una subversión en el ámbito social.

Por otro lado, es condición indispensable que toda obra utópica sea irrealizable desde el punto de vista social. Puede funcionar como un medio de transformación para romper con el modelo existente, pero si se llegase a hacer realidad, se fundaría un nuevo orden y se entraría dentro de la paradoja. Normalmente, suele aplicarse el concepto a todos aquellos proyectos urbanos una vez que la época en la que se gestaron ya ha pasado. De hecho, las utopías suelen utilizar la imaginación ${ }^{1}$ para aislarse de la realidad existente en busca de lugares y épocas deseables y felices, a la vez que expresan las carencias reales de la sociedad, como se puede observar en los cuentos, las fantasías humanistas, los libros de viajes o los sueños. Esta caracterización lleva a la comprensión de la utopía como un género o un subgénero literario particular cuya finalidad es la proyección de mundos posibles desde la ficción. Deben considerarse como una representación de lo real en el imaginario del poder que lleva a que esta parezca

\footnotetext{
${ }^{1}$ Mannheim sostiene que no puede aplicarse el concepto de utopía a las manifestaciones literarias en un sentido estricto. A pesar de que representan una sociedad opuesta a la real, no potencian ni el cambio ni la desintegración de lo conocido, únicamente reflejan el anhelo de cambio. De ahí que diferencie entre "proyecciones temporales" y "proyecciones espaciales", entendiendo las espaciales como utopías y las temporales como quiliasmos (1966: 282-299).
} 
como no vivible o no experimentable en el orden social, es decir, que se muestre como un mundo posible, paralelo y contrapuesto al real, a pesar de no ser así (Facuse 2010: 203).

En este sentido, la utopía, casi por definición, enfatiza el carácter fantástico e irreal de la ciudad planteada, pero sin olvidar el trasfondo social, ético y político. Así, puede entenderse como el sueño de un estrato social descontento con el espacio urbano en el que vive. Proyecta una organización mejor a la existente, ya sea mediante el sueño o el deseo de integración de un personaje concreto de la sociedad que se materializa a través de la presentación de un constructo urbano perfecto, igualitario e integrador. En este caso, se planteará como la experimentación y la puesta en práctica de un modelo social en un espacio urbano que pretende alcanzar el ideal, pues ese es el objetivo y la finalidad de cualquier utopista, independientemente de la forma o del contenido más o menos crítico.

\section{UTOPÍA Y NARRATIVA ESPAÑOLA}

Aplicar los conceptos manejados anteriormente a la narrativa española puede resultar controvertido, ya que la crítica ha mostrado poco interés en este campo y las conclusiones obtenidas son contradictorias. A penas se conocen datos sobre las utopías anteriores al siglo XIX, por lo que se suele relacionar la utopía con textos de naturaleza política, apuntándose en algunos casos que El Quijote (1605) posee algunos rasgos que pueden considerarse como un antecedente de la utopía política (Manuel 1971). Esto lleva a que numerosos críticos como Ortega y Gasset (1993), Núñez Lavedeza (1976) o, más recientemente, Sargent (2001) afirmen que la tradición utópica española es nula o, como mucho, escasa si se tienen en cuenta los textos de carácter marxista. Sin embargo, sí que se pueden rastrear fragmentos de carácter utópico insertados en obras mayores durante los siglos de Oro hasta la aparición de Sinapia, considerada como la primera obra utópica en su totalidad.

Para realizar el recorrido utópico en la narrativa española, es necesario partir de la afirmación de Mumford (2013) que sostiene que el momento de mayor esplendor de la utopía europea se encuentra tras el descubrimiento de América. De hecho, la visión que ofrece Colón a través de sus cartas y diarios, comparando la tierra recién descubierta con el Paraíso, ejerció influencia en los tres autores más destacados de la literatura utópica europea: Moro, Bacon y Campanella. Si fue la corona de Castilla quien financió la travesía y llevó a cabo la colonización del Nuevo Mundo, es lógico pensar que la narrativa castellana también desarrollase modelos utópicos. A partir de los rasgos comunes entre los escritos de Colón y los autores mencionados, se puede deducir, siguiendo el trabajo de Mumford (2013), que, junto con la recuperación del ideal griego, el descubrimiento de América y la imagen proyectada por Colón a través de sus cartas, nace el clima intelectual perfecto para el desarrollo en Europa del movimiento utópico.

La colonización de América distrajo la atención del mundo imaginario e hizo que se posase la vista sobre el ámbito de la realidad, porque los españo- 
les tenían la posibilidad de hacer reales sus proyectos urbanos. Además, nos situamos en un momento en el que la Inquisición ejercía una enorme influencia sobre los humanistas y es probable que se prohibiese la creación de ciudades perfectas e ideales sin la intervención única y directa de Dios. De ahí que NuñezLavedeza o Eliav-Feldon (1982) nieguen la existencia de utopías renacentistas coetáneas con las de Bacon, Moro o Campanella. A este respecto, resulta interesante el estudio de Eliav-Feldon quien concluye que el momento de máximo esplendor utópico en Europa se desarrolla entre 1516 y 1630, lo que lleva a que en España se desarrollase de forma tardía. A partir de la publicación de Sinapia, se establecerán las características formales y temáticas del género, a la vez que se dificulta su introducción dentro del canon europeo.

Destacan las fechas de 1975 y 1976, momento en el que Stelio Cro y Miguel Avilés descubren y publican, casi simultáneamente, un manuscrito encontrado en la biblioteca del conde de Campomanes titulado Sinapia y del que se desconoce su autor. Esto supone, no solo la afirmación de que en España sí hubo un movimiento utópico, sino también que no se dio en un sentido estricto, es decir, las utopías españolas ocupan un lugar especial en comparación con las francesas, las inglesas o las italianas, ya que los modelos urbanos ideales se realizan desde una perspectiva diferente al modelo europeo. Se diferencian de estas porque su temática está condicionada por el descubrimiento y la conquista de América que ha dirigido el género a otras disciplinas alejadas del ámbito estrictamente literario (Cro 2005: 44). Esta circunstancia es la que, a nuestro juicio, ha dado lugar a un género fronterizo e híbrido que ha quedado relegado a la periferia del sistema por los cruces constantes entre la ficción y la no ficción.

Lo cierto es que sí hubo manifestaciones anteriores a Sinapia como Somnium de Juan de Maldonado $(1532)^{2}$ que supone la primera creación literaria española de carácter utópico ${ }^{3}$ e incluye elementos que hacen pensar en un posible antecedente de la ciencia ficción española, ya que contiene el primer viaje a la luna realizado en la narrativa española. Junto a la obra de Maldonado, destacan dos textos cervantinos que plantean la configuración del género utópico, dirigida hacia la forma que tomará en Sinapia. A través de La Galatea (1585), Cervantes presenta un modelo de base agrícola basado en el mito de la Edad de Oro y refutado en El Quijote mediante el uso de la ironía, destacando especialmente el episodio de la ínsula Barataria.

Este pequeño recorrido de carácter histórico no solo afirma la existencia de un movimiento utópico en la narrativa española anterior a Sinapia, sino también la necesidad de interpretarlo partiendo del hecho de que nos encontramos ante constructos diferentes que poseen la esencia que permite caracterizar el género, pero planteados de forma diferente. El rasgo que hace las utopías hispa-

\footnotetext{
2 En el periodo en el que Maldonado escribe el sueño lunar, se pueden rastrear diversos fragmentos en obras mayores, siendo el más destacado "El relato del Danubio", perteneciente al Reloj de príncipes de fray Antonio de Guevara (1539).

3 Francisco López Estrada (1981) y Fernando Gómez Redondo (1982) apuntan a que en la Edad Media se pueden rastrear elementos utópicos a través de diversos exempla que apuntan hacia la utopía desarrollada por los humanistas.
} 
nas diferentes a las europeas es su contenido, focalizando más en la política, la filosofía y la geografía que en la literatura propiamente dicha. De hecho, el propio autor de Sinapia afirma en la introducción que busca huir lo máximo posible de la ficción. Trata de evitar que su obra se entienda como una novela, buscando dar a su contenido un mayor grado de verosimilitud, como deja explicitado en el siguiente fragmento:

Determinéme, pues, a traducirla, a riesgo de que pase por novela, por la dificultad con que los que nos habemos criado con lo mío y lo tuyo podemos persuadirnos que pueda vivirse en perfecta comunidad y los que estamos hechos a la suma desigualdad de nobles y plebeyos difícilmente creemos pueda practicarse la perfecta igualdad. [...] Finalmente, verdadera o verosímil, es muy digna de alabanza esta república, pues ha logrado el mejor fin que puede pretenderse o, a lo menos, ha dado ejemplo a los que lo quisieren lograr. (Anónimo 1976: 70)

Los autores ofrecen al lector la descripción de un mundo feliz en el que habita una sociedad perfecta e ideal que contrasta y critica el mundo real que se presenta mediante la utilización de un tiempo presente en relación con la narración. En este sentido, Miguel Avilés (1982: 30-31) realiza una diferenciación basada en el tiempo en el que se sitúan. De esta forma, si la utopía se sitúa en un tiempo pasado, la ciudad aparece descrita como un paraíso perdido, reforzándose el mito de la Edad de Oro y haciendo hincapié en que esa comunidad perdió la felicidad por algún hecho, como se observa en capítulo XI de la Primera Parte de El Quijote. Por el contrario, si la utopía se sitúa en un tiempo futuro, constituye un proyecto para construir una ciudad perfecta al tiempo que asegura que la sociedad será tal cual se perfila. Este tipo de proyecciones se observan, fundamentalmente, en textos de carácter marxista como La Nueva Utopía de Ricardo Mella (1890). Por último, si las utopías se inscriben dentro del presente, proyectan la construcción de una sociedad ideal basada en un modelo del presente, como en el caso de Sinapia.

2.1. Somnium y Barataria. La relación isla-espacio utópico en la narrativa española

El proyecto utópico comenzó a relacionarse con el espacio de la isla a partir de la aparición de Utopía de Tomás Moro (1516). La isla se convierte en un espacio identitario de búsqueda de un ideal de vida ansiado por los escritores que representa un lugar de abstracción política y de cambio social. Se presenta como irreal $y$, en ocasiones, rodeada de un halo de misterio debido a los diferentes seres mitológicos que habitan en ella. Suele asociarse a la imagen del paraíso terrenal, dominado por la Naturaleza y donde los habitantes conservan los valores ancestrales que les permiten ser felices. Precisamente, este imaginario que ofrece el terreno insular es lo que la convierte en el espacio utópico perfecto, impulsado como un espacio-tipo tras la obra de Moro.

La concepción de la isla como espacio mítico ya aparece en la Antigüedad, concretamente en La Odisea, donde Homero sitúa al héroe épico en diversas 
islas como la Isla de Eolo o la Isla de Helios. Platón también sitúa en las islas de Calípolis, Atlántida y Magnetes su modelo de ciudad ideal. Los escenarios presentados por ambos autores se pueden definir como un reducto imaginario que alberga un pequeño universo cerrado y aislado del resto del mundo. Es poseedora de su propio espacio y tiempo, por tanto, su vida cotidiana puede presentarse bajo condiciones especiales en las que juega un papel fundamental lo maravilloso y permite que su morfología urbana se presente como perfecta. Otro de sus rasgos fundamentales es la aparición de enigmas y misterios a los que debe enfrentarse el héroe que llega a ella y que suponen una de sus características imprescindibles.

Cuando un náufrago llega a la isla procedente de la civilización, si logra adaptarse a su forma de vida, encontrará un espacio perfecto y podrá disfrutar de la felicidad que este le produce. Se presentará como un héroe más fuerte, más sabio y más virtuoso que al comienzo de la trama. Por el contrario, si no logra adaptarse, la isla se convertirá en un espacio de sufrimiento para él. De esta afirmación se concluye que el carácter utópico de la isla se ofrecerá a partir de dos perspectivas diferentes. Por un lado, el narrador la describe desde el prototipo creado por la imaginería popular: aislada, perfecta, paradisíaca, feliz y llena de enigmas y de personajes procedentes de la mitología como sirenas o monstruos marinos. Por otro, la isla se nos presenta desde el punto de vista del héroe que llega a ella desde la civilización, una aventura que puede ser positiva o negativa para él.

La isla, como espacio utópico, aparece en la narrativa española tanto en los libros de viajes medievales, como en las novelas de caballerías y se reforzará tras la traducción de la obra de Moro. Durante el Renacimiento, representa el anhelo de quien busca escapar de la miseria, la pobreza y el caos de la realidad. En el Barroco, dejará de ser el espacio utópico por excelencia para dejar paso a los espacios urbanos. Se reforzará el contenido político y social y se descargará la utopía de elementos míticos y fantásticos. La concepción de la isla que se maneja durante el Renacimiento, en conexión con el descubrimiento de América, nos permite entender la aparición de manifestaciones utópicas como Somnium de Juan de Maldonado. El ideal de felicidad y de belleza que Maldonado encuentra en América se modificará en El Quijote, donde la isla maravillosa que se le ofrece a Sancho para huir de la miseria será Barataria, un reducto aislado que se le presentará como un lugar de sufrimiento y donde el interés del narrador radica en el aspecto político-social de la misma. La comparación de ambas obras permite ver cómo se modifica el espacio utópico encaminándose cada vez más hacia los modelos urbanos al desnudarse progresivamente de los elementos fantásticos (sueños, aventuras con seres mitológicos, enigmas, misterios...) hasta desembocar en Sinapia.

Una parte del viaje de Maldonado refleja una utopía de carácter social, pues al finalizar su viaje a la luna, el protagonista cae en una tierra americana y describe la feliz vida de los indígenas a modo de paraíso terrenal, conectando de esta forma con la idea planteada anteriormente en relación con los escritos de Colón y su influencia en los autores españoles. A través del recurso del sueño, Juan Maldonado plantea un viaje espacial y una pequeña incursión en el Nuevo 
Mundo, utilizando una serie de mecanismos con la finalidad de dotar al texto de un mayor grado de verosimilitud, sobre todo en lo que a los episodios utópicos se refiere. En primer lugar, el sueño aparece insertado en unas coordenadas espacio-temporales precisas. Maldonado, el protagonista, se encuentra en una torre de la muralla de Burgos en una noche de mediados de octubre esperando el paso de un cometa cuando se queda dormido.

El sueño en su conjunto no constituye un universo paralelo al real, sino que aparece relacionado directamente con la realidad a la vez que crea un constructo condicionado por el estado de ánimo del personaje antes de dormirse. De ahí que el narrador remarque la contemplación de los astros, sobre todo de la luna. Su visión viene definida por el platonismo cristiano como una identificación directa con la verdad. Esta visión se sitúa en el espacio, por lo que sus observaciones se acercan a la perfección, precisamente por su proximidad con el ámbito celestial. Al observar la misma realidad lunar en la tierra, fundamentalmente en el caso de la ciudad indígena, llega a la conclusión de que es posible que el hombre ponga en práctica el modelo de convivencia social visto en esferas superiores guiándose por la razón y la fe. Los modelos utópicos planteados, tanto la ciudad lunar como la indígena, destacan por ser sociedades felices, desprovistas de avaricia y de lujuria. Todo es paz, inocencia y bondad. Así, la sociedad americana destaca por la ausencia de leyes que castiguen o rijan el comportamiento de sus habitantes, ya que sus moradores viven en un paraíso que recuerda el mito de la Edad de Oro.

Las resonancias del tópico del locus amoenus que se pueden observar en las descripciones de la obra de Maldonado serán recuperadas por Cervantes a través de la imaginería de Barataria, la ínsula prometida a Sancho Panza. Cervantes, a lo largo de la novela, evoca lugares apacibles en una situación privilegiada, con un buen clima y una frondosa vegetación. Se trata de regiones fecundas y donde abunda la miel, alimento divinizado junto al néctar y la ambrosía. Muchos de estos parajes se sitúan en lugares aislados y alejados del paso del tiempo y de la potente y malvada mano de la civilización. Barataria será la encarnación de este ideal utópico, construido sobre la farsa y la ironía desde la base. El héroe canónico alcanza un reino que por norma general está separado de su propio mundo y tiene que atravesar bosques, ríos de fuego, mares... superando un sinfín de peripecias. Su paraíso soñado está aislado y lejos del espacio por el que habitualmente se mueve. Por el contrario, Barataria se situará en tierra y no muy alejada de la aldea de Sancho que, como cualquier héroe, también debe realizar pruebas para dejar constancia de su valor y entrega y demostrar que es la persona adecuada para ostentar el cargo de gobernador. En este caso, cabe destacar que el término ínsula se refiere a un lugar aislado y acotado. Tal y como sostiene Antonio Santos:

Se trata de un término que reconcilia, pues, lo sacro con lo profano; lo mundano con lo espiritual. Pero también lo antiguo con lo moderno; lo real con lo imaginario; y siempre vinculándolo con el aislamiento o la reclusión, el apartarse del resto del mundo. Esta es la acepción que al margen de su conexión como isla ficticia, conserva Barataria. (Santos 2008:99) 
La parodia que genera Cervantes con Barataria gira en torno a tres ejes fundamentales. En primer lugar, la ínsula no pertenece a ningún continente o geografía imaginaria. Se accede a ella por tierra e incluso se encuentra próxima a su punto de partida. En segundo lugar, no hay una localización geográfica precisa y se ofrecen las mínimas referencias urbanas en cuanto a número de habitantes o a su morfología. Por último, Sancho cree encontrar en Barataria un paraíso, un espacio perfecto e ideal tal y como don Quijote le anuncia desde el comienzo de su andadura. Por ello, se concibe Barataria como una utopía. Sin embargo, su ínsula es una farsa urdida por el Duque para burlarse del escudero. Como lectores, nos formamos la misma idea utópica que Sancho al verse gobernador de la misma, introduciéndonos en un interesante juego entre la realidad y la ficción. Sabemos que Barataria es una ficción y sus habitantes los actores que ejecutan la farsa, mientras Sancho actúa desde el plano real, desconociendo que todo es un teatro planificado por el Duque, y pone en práctica un gobierno basado en la virtud y en los valores liberales que su amo le ha inculcado.

La vida cotidiana en Barataria resulta monótona, pues se basa en el cumplimiento del deber y en la ausencia de placeres o diversiones. Sancho rige su gobierno con censura, imposición del orden y autoridad, controlando el trabajo, las relaciones sexuales y prohibiendo la vagancia y la ociosidad al pretender cerrar los pocos lugares de ocio que quedan. La economía insular se basa en un modelo primitivo muy similar al que don Quijote mencionaba en el episodio de los cabreros y muy en relación con la Edad de Oro: "Lo que puedo daros doy, que es una ínsula hecha y derecha, redonda, bien proporcionada, y sobre manera fértil y abundosa, donde si vos os sabéis dar maña podéis, con las riquezas de la tierra, granjear las del cielo" (Cervantes 1996: 693). Al igual que en Utopía de Moro, Sancho se convierte en una especie de rey Utopos que rige con mucha severidad el destino de los habitantes e imparte justicia de una forma salomónica, como se observará en diversos episodios como el de los hermanos travestidos cuyo objetivo es salir de su casa y conocer el exterior, lo que supone un elogio a la libertad.

Tras la guerra y la derrota de Sancho como gobernador, este decide abandonar el espacio ficticio y utópico para volver a su realidad. La ironía radica en el hecho de que Sancho propone un modelo de gobierno basado en la justicia y la igualdad en un reino ficticio cuya pretensión es burlar al gobernador. La utopía de Barataria no pretende transformar la sociedad o eliminar la propiedad privada. Únicamente se centra en imponer justicia, dar una manutención al necesitado y promover la bondad y la compasión, tal y como ha venido enunciando don Quijote. La finalidad del episodio de Sancho en Barataria es corregir las peleas, las rencillas, los pleitos, la ociosidad y el gobierno corrupto que no ofrece soluciones a los problemas de los vecinos. Estas soluciones conforman el aparato irónico sobre el que se sustenta la utopía social. La nobleza y la entrega del escudero chocan con la tiranía del aristócrata, cuyo poder se basa en la maldad y la ociosidad, a la vez que infunde miedo a los habitantes para evitar una sublevación. 
Por el contrario, Sancho es admirado por el pueblo durante su corto gobierno. En este sentido, la utopía trazada en Barataria toma dos perspectivas: una positiva y otra negativa. La positiva será la de los habitantes que, a pesar del engaño y la burla que en un principio pretenden, descubren una nueva forma de gobierno más satisfactoria que la anterior, mientras que para Sancho la utopía vivida es totalmente negativa a causa de su trabajo y el sufrimiento en el que se convierte su vida. La visión del escudero es la que nos lleva a ver en Barataria la imposibilidad de materializar una utopía. La utopía es perfecta y hermosa cuando es un proyecto, un sueño o una ilusión. Por el contrario, si logra materializarse se transforma en falsedad, ironía y sufrimiento. La utopía, siguiendo la definición de Mannheim, debe plantearse como una válvula de escape a los problemas sociales y a la crisis y en el momento en el que se materializa deja de ser tal para convertirse en Barataria.

El sueño que don Quijote proyectó para Sancho desaparece justo en el momento en el que el escudero va a hacerlo realidad, por lo que después volverá a reunirse con su señor y a continuar su camino, intentando implantar la sociedad caballeresca que don Quijote enuncia al principio de la novela. Pretende imponer el bien y que la edad dorada vuelva a reinar sobre la tierra. Sin embargo, su aventura es un fracaso tras otro. Se debe a que su proyecto es puesto en práctica de forma individual, cuando una utopía social, cuya finalidad es la creación de un espacio ideal y feliz, no puede ser una empresa individual, sino colectiva. Este hecho deja patente que el modelo de base agraria y caballeresca que Cervantes defendía, ahora ya no sirve. Únicamente es defendido por un pequeño grupo de hidalgos empobrecido y enrocados en unos ideales que deben cambiar, como así se plantea desde el comienzo de El Quijote.

Parece que la empresa de don Quijote, su utopía, ha fracasado y llega a su fin con su muerte. Sin embargo, es Sancho Panza quien se hace cargo del legado utópico de su amo y quien continuará defendiéndolo. Este hecho nos lleva a pensar que Cervantes era consciente de que el modelo utópico tenía que cambiar e incluso introduce ciertas modificaciones que serán tratadas con mayor profundidad en manifestaciones posteriores. La más destacada es el paso de la isla a la ciudad como espacio utópico por excelencia. Esto no significa un giro radical en la concepción del espacio, sino que a partir del episodio de Barataria, se focalizará más en espacios urbanos definidos que en las islas maravillosas perdidas en el océano que pasarán a ser el escenario de los libros de aventuras, por lo que las obras utópicas tenderán a descargarse de contenido fantástico. A pesar de ello, Cervantes se da cuenta de que el cambio todavía no va a realizarse por completo en el momento en el que don Quijote comienza su periplo. De ahí que entendamos la utopía cervantina, no solo como una ironía, sino como un punto de inflexión y de modernización de la corriente utópica española que avanza lo que vamos a encontrar durante la llustración a través de Sinapia.

\subsection{Sinapia. Un paraíso en tierra austral}

Durante el siglo XVII, hubo muy pocas manifestaciones utópicas en la narrativa española. En el siglo xVIII, se desarrollan con más fuerza tras la traducción de la 
obra de Moro y la difusión de las utopías extranjeras. Sin embargo, no surgen con la fuerza con la que se desarrollan en Francia. La mayoría de las utopías hispanas forman capítulos de obras más extensas o se publicaron en periódicos del momento a modo de discursos o proyectos de reforma política-social (Martínez 2006: 258). ${ }^{4}$ Entre otras, destaca Sinapia, el resultado del modelo en fase de transformación que se encuentra en la Barataria cervantina. A pesar de la controversia en cuanto a su datación, vamos a entenderla como una utopía del siglo XVIII basándonos en los modelos urbanos que presenta. Sinapia es el primer texto utópico descubierto en la narrativa española. De todas las utopías hispanas, es el más estudiado y sobre el que más polémica se ha generado en torno a su fecha de composición y autoría. Independientemente de quién sea su autor y del momento en el que fue gestada, lo importante del hallazgo es que esta obra nos permite profundizar en el conocimiento del género en el ámbito hispano y ver la diferencia con las utopías canónicas en cuanto a la primacía del contenido social.

Por otro lado, su redacción coincide con un momento en el que se cree en la existencia de un continente lejano, la tierra austral, y los utopistas comienzan a dar una ubicación espacial precisa y fácilmente identificable con este territorio. Como se ha planteado anteriormente, la ciudad ideal enclavada en países lejanos y exóticos es el marco perfecto para el desarrollo de la utopía social, pues a través de la ficción se modifica el espacio real y se da pie a la formulación de uno nuevo en el que proyectar y describir nuevas estructuras sociales que conformen la propia utopía. Se presenta entonces como una crítica implícita del presente que busca cambiar la realidad. A partir del siglo XVIII, las narraciones utópicas se presentarán bajo la forma de relatos de aventuras o de viajes que critican las desigualdades sociales y los privilegios de las altas clases sociales, a la vez que proponen una organización territorial. En el caso de Sinapia, se presenta a toda una nación en la tierra Austral, uno de los espacios utópicos más admirados hasta principios del siglo XIX.

Las utopías de los siglos de Oro únicamente describen el gobierno de una ciudad ideal, mientras que ahora se propone una nueva organización territorial y la forma en la que esta ha de ser gobernada. Así mismo, Sinapia supone una novedad en cuanto al espacio elegido, pues además de introducir la tierra austral, deja de lado la imagen de ciudad ideal circunscrita a la noción de "isla perdida y lejana" que se observa en el caso de Somnium y traslada el ideal de una comunidad pequeña a un país entero. Rompe con la estructura administrativa y geográfica de una nación y propone una división territorial geométrica de idéntica superficie e importancia jerárquica. Su autor es capaz de definir y delimitar sus fronteras, así como de proponer un sistema de defensa en caso de invasión.

\footnotetext{
${ }^{4}$ A este respecto, cabe destacar las Fábulas de Iriarte, interpretadas como microutopías por José Luis Calvo Carilla: "Con la publicación de sus Fábulas, Iriarte realizó una novedosa apuesta literaria al imaginar un conjunto homogéneo de viñetas satíricas en las que aplicó con fortuna el fustigat ridendo mores a los excesos y vicios de la literatura barroca y a la feria de ignorancias y vanidades de quienes pertenecían al cotarro literario. El 'alma' o 'aviso' de estas microutopías ofrece una intención y unos contenidos similares a los de otras muchas muestras de su tiempo..." (2008: 98).
} 
La idea que remarca es que la mejor organización es la de la estructura socioespacial colectiva y el fomento de la conciencia de comunidad por encima de la individualidad de sus habitantes.

La república de Sinapia constituye un modelo de sociedad ideal en la que tanto el gobierno como la iglesia se esfuerzan para que todos los habitantes sean felices, pero siempre dentro de un orden reglamentado y racional, regido en torno al racionalismo de Descartes. El texto se organiza en 33 apartados que se pueden agrupar en cinco bloques y que nos permitirán conocer pormenorizadamente la organización de un Estado perfecto desde sus orígenes hasta la geografía de su asentamiento, la religión y la organización política, administrativa y social. La obra finaliza con una valoración sobre los esclavos y el enclave tan singular de la tierra austral. Esta imaginaria tierra debe entenderse como la exposición de un proyecto de nación ideal. En ella vive una comunidad perfecta, igualitaria y cuya religión se centra únicamente en el culto a Dios. Sus ideales de vida son la igualdad, la moderación y el trabajo, entendido como una necesidad y una fuente de dignidad para el ciudadano. Por el contrario, en Hispania se vive en total desigualdad y los gobiernos únicamente están atentos a satisfacer las pasiones y los vicios de un grupo determinado en detrimento de la comunidad. A este respecto cabe destacar el hecho de que su autor ha sido consciente del enfrentamiento entre nobles y plebeyos que se estaba llevando a cabo en el momento de su gestación, indispensable según la teoría de Mannheim para que se dé la utopía. Su anónimo autor entiende que el problema radica en la soberbia y en la ambición de una clase que oprime a los plebeyos.

Dentro del espacio urbano, existen una jerarquía y un organigrama similares a los de Hispania, ya que por encima de la ciudad se encuentra la metrópolis o capital de la nación donde vive el príncipe. Resulta novedoso el planteamiento que realiza su autor con respecto al trazado, explicando las diferencias entre unas zonas y otras. Cada núcleo urbano se define en función del número de habitantes y de dotaciones y equipamientos. Así mismo, marca límites entre las ciudades para evitar su crecimiento desmesurado, mediante el uso de arboledas o pirámides de ladrillo en los puntos de encuentro. También fija un número máximo de habitantes en el barrio, en la villa, en la ciudad y en la metrópolis y concreta que una ciudad nunca podrá exceder de las 1200 familias y cada una de ellas contará con un máximo de 12 miembros. Sin embargo, la relación entre las villas y los barrios es confusa. Lo más destacado del texto es la idea de subdivisión y organización racional basada en el orden radical y exponiendo con total claridad los condicionamientos físicos o históricos que le permiten agrupar los distintos núcleos en zonas urbanas o rurales. La ciudad queda, por tanto, definida de la siguiente forma:

Las ciudades son poblaciones cuadradas con su muralla y su foso, compuestas de barrios, al modo que las villas; divididas en parroquias y en cada una su templo y, enmedio, el mayor, con las viviendas de los eclesiásticos alrededor y sus cuatro casas del común de la ciudad. No puede exceder el número de las familias 1200, fuera de los magistrados de parroquias y ciudad, estudiantes y esclavos públicos. (Anónimo 1976: 84) 
La ciudad situada en el centro de cada provincia cumple las funciones de capital provinciana y en ella están los magistrados, los obispos y la catedral. Siguiendo la ordenación jerárquica que plantea, la Corte se situará en la metrópolis central de la península y cumplirá las funciones de capital de la nación. Sinapia presenta, a través de las estructuras urbanas, el modelo de comunidad ideal partiendo desde la base social: la familia, y llegando a la instancia más alta del Estado: el príncipe. Esta organización urbana es coherente con la comunidad ideal que pretende alcanzar, basada en la convivencia comunitaria pacífica, en la comunidad de bienes y en la igualdad de sus miembros. En este sentido, constituye un ejemplo de utopía social en el que la organización territorial y la política están estrechamente relacionadas con la finalidad de conseguir una comunidad disciplinada, trabajadora y homogénea, un planteamiento similar al que se encuentra a finales del siglo $x I X$.

2.3. De la utopía marxista a la ciudad vanguardista. La mecanización del espacio urbano

A partir de la revolución francesa, el mito de la Edad de Oro comienza a desvanecerse. Durante el siglo XVIII se empieza a creer que la humanidad solamente va a poder encontrar la felicidad a través del enriquecimiento, es decir, mediante el progreso basado en la técnica, un hecho que ya se plantea en Sinapia. Esta nueva manera de ver la sociedad perfecta tomará forma durante el siglo XIX, momento en el que se observan los primeros pasos hacia la sociedad capitalista, lo que hace que la utopía se impregne de las nuevas formas sociales y que busque el bienestar en lo material. Así, la industria y la técnica deben estar al servicio de la riqueza, de la abundancia y de la justicia para que todos los trabajadores puedan vivir con las mismas comodidades que los burgueses.

El liberalismo y la crudeza capitalista hicieron que los obreros se empobreciesen aún más. Las ciudades se readaptaron a la vez que se empobreció el centro urbano, puesto que era el espacio que ocupaban los obreros por su cercanía a las fábricas. La mayor parte de la clase trabajadora procedía del campo y carecía de una especialización, por lo que su salario era escaso y apenas daba para sobrevivir. Tampoco contaban con protección social en caso de que se especulase con los salarios, se quedasen en el paro o padeciesen una enfermedad que les impidiese trabajar. A esto hay que sumar las condiciones deplorables en las que tenían que trabajar y vivir, lo que provocó no solo el deterioro del centro de la ciudad, sino también una clase trabajadora desmoralizada, empobrecida y donde abundaban la criminalidad, la prostitución y el alcoholismo.

Esta situación lleva a que las élites sociales que estaban obligadas a convivir con la clase trabajadora comiencen a desplazarse hacia las afueras de la ciudad, huyendo del humo asfixiante de las fábricas y evitando el contacto con las clases sociales más bajas y el contagio de enfermedades. Este hecho trae consigo la conformación del suburbio, un espacio reservado para la burguesía y la aristocracia. Su aparición constituye un elemento clave para entender la formación del actual espacio urbano, sobre todo en lo concerniente a los pro- 
cesos de gentrificación estudiados por Janoschka (2011) y Sequera (2014) y la formación de periferias. Este nuevo espacio tomará la forma de un retiro idílico cuyas viviendas serán muy semejantes entre sí arquitectónicamente, estarán separadas, evitando el hacinamiento del centro, y se situarán próximas a parques y jardines. Las altas clases sociales buscan espacios abiertos y libres de contaminación, puesto que el centro se ha convertido en un espacio cerrado, asfixiante y peligroso (Mumford 2012: 803-875).

Será precisamente la nueva planificación urbana del suburbio la que se desarrolle en los modelos utópicos de este periodo, destacando su belleza, la ausencia de contaminación y el contacto con la vida rural. De hecho, la ciudad diseñada por Ricardo Mella en La Nueva Utopía es muy similar a la de un suburbio, separando la zona de las viviendas de las fábricas y dedicando una parte a zonas verdes de juego para los niños, tal y como se observa en el siguiente fragmento:

En su lugar se han levantado grandes edificios perfectamente alineados, separados por pequeños jardines, donde juegan alegremente los niños de la vecindad. Una parte de la ciudad está dedicada exclusivamente a las viviendas y al otro lado se ven tan solo inmensas fábricas, talleres, granjas de labor en las afueras, grandiosos mercados, conjunto hermoso y grandilocuente de todas aquellas manifestaciones de la actividad humana, del trabajo. (Mella 1890: 4-5)

Mella reflexiona sobre la organización de una sociedad sin clases, ni leyes, ni aparato estatal. El modelo que presenta responde a la utopía anarquista ${ }^{5}$ clásica desarrollada a finales del $\mathrm{XIX}$ y principios del $\mathrm{x} x$, poseedora de grandes expectativas basadas en la ciencia y el progreso técnico. Defendía una sociedad no capitalista, no individualizadora y libre, por lo que el orden social negaba en sí mismo la necesidad de leyes y Estado, por tanto, la comunidad únicamente va a estar regida por las leyes de la Naturaleza. Presenta una sociedad futura basada en el progreso, la igualdad social y ausente de prácticas capitalistas. El anarquismo devuelve la paz y la armonía a un pequeño pueblo situado a orillas del Cantábrico y reestablece la libertad y la dignidad de sus habitantes al mecanizar y adaptar a los nuevos tiempos una aldea de pescadores. Utiliza este nuevo modelo urbano para condenar la sociedad capitalista conformada tras la Segunda Revolución Industrial remarcando las bases sobre las que debe sustentarse la sociedad futura: la libertad y la igualdad de las que emana una convivencia pacífica e idílica basada en el acuerdo y el pacto entre los hombres.

Tras varios siglos de adaptación, el pequeño pueblo de pescadores se transforma en una moderna ciudad de la mano de la ciencia. La pobreza característica de las zonas urbanas donde viven hacinados los trabajadores y en condiciones de insalubridad deja paso a viviendas construidas de forma similar a las de los nacientes suburbios, lugares reservados para la burguesía y la aristo-

\footnotetext{
5 Junto a la ficción utópica anarquista cabe destacar la obra de Wenceslao Aywals de Izco. En este sentido, se debe tener en cuenta que la obra de Aywals de Izco no se adapta en cuanto a su forma a las convenciones del género. Sin embargo, su contenido entronca tanto con la utopía literaria como con la utopía reformista de carácter político (Calvo 2008: 115).
} 
cracia. Ahora la ciudad se dividirá en dos espacios: uno para las viviendas y otro para las fábricas. Las viviendas se sitúan perfectamente alineadas, presentan la misma morfología y poseen jardines para que los niños puedan jugar en lugar de trabajar, como ocurre en la ciudad capitalista. Los distintivos de la nueva ciudad serán el hierro y la electricidad, como así se refleja en el siguiente fragmento:

El amontonamiento de las viviendas, la lobreguez de las habitaciones, el reducido espacio y el acotamiento de las alcobas, el inmundo contubernio del basurero y la cocina, el dormitorio y el comedor; la caprichosa alineación de las calles, todos los restos del sistema antiguo han desaparecido en absoluto de la "Nueva Utopía". En su lugar se han levantado grandes edificios perfectamente alineados, separados por pequeños jardines, donde juegan alegremente los niños de la vecindad. Una parte de la ciudad está dedicada exclusivamente a las viviendas y al otro lado se ven tan solo inmensas fábricas, talleres, granjas de labor en las afueras, grandiosos mercados, conjunto hermoso y grandilocuente de todas aquellas manifestaciones de la actividad humana, del trabajo. (Mella 1890: 4-5)

Todas las viviendas poseen calefacción, limpieza, seguridad y modernos ascensores. Las antiguas cabañas de pescadores de madera se han convertido ahora en edificios modernos de hierro y piedra o ladrillo y se encuentran separadas entre sí por zonas verdes para evitar las aglomeraciones y los hacinamientos de las metrópolis. La ciudad presentada por Mella se dirige hacia el progreso científico y la dominación de la Naturaleza por parte del hombre. La Nueva Utopía encarna el modelo de ciudad moderna electrificada donde la máquina y la ciencia juegan un papel fundamental, características que se retomarán tanto en obras de ciencia ficción (Mecanópolis de Miguel de Unamuno, 1913) como en textos vanguardistas (La ciudad automática de Julio Camba, 1932). ${ }^{6}$ Asistimos pues al planteamiento de la relación ciencia-ciudad que con el paso del tiempo derivará en la ciencia ficción. Tanto en la obra de Mella como posteriormente en la de Camba se construye la expresión de una época y la cristalización del sueño de Occidente: el progreso llevado a su máximo exponente y entendido como una condición indispensable para lograr la felicidad. En este caso, la felicidad únicamente se hallará a través del movimiento anarquista ${ }_{1}^{7}$ la única utopía de futuro que puede hacerse realidad.

En relación con la modernización y la mecanización de los espacios urbanos, nos encontramos con el modelo de ciudad americana planteada a partir de los años 20, momento en el que el mito de Nueva York crece paulatinamente

\footnotetext{
${ }^{6}$ La ciudad automática recoge los artículos que Julio Camba publica durante su estancia en Nueva York. En 1917, publica Un año en el otro mundo, un libro con las mismas características que La ciudad automática y en el que recoge las impresiones que le produce la ciudad de Nueva York durante su primer viaje como corresponsal.

7 Durante la primera mitad del siglo xx (hasta 1936) y tras la fundación de la CNT en 1910, la utopía literaria de carácter anarquista va perdiendo peso en favor de la proclama política, abandonando el ámbito estrictamente ficcional para centrarse en la teoría política. A partir de este momento, no se encontrarán prácticamente manifestaciones literarias similares a La Nueva Utopía de Ricardo Mella.
} 
convirtiéndose en el modelo de ciudad perfecta en sustitución de París (Alarcón 2015: 11). La ciudad americana es un espacio que acoge a un gran número de inmigrantes y que potencia una imagen de convivencia multicultural que conecta con el espíritu cosmopolita de los escritores vanguardistas. Sin embargo, la realidad es que la acogida de inmigrantes originó un grave problema con la vivienda. Así se reorganizó la ciudad separando los barrios según la procedencia y la clase social de cada habitante. Esto trajo consigo el desarrollo del metro y del tranvía, posibilitando la formación y el asentamiento de las modernas periferias, conformadas por barrios pobres, poblados en su mayoría por inmigrantes que vivían hacinados y en condiciones de insalubridad, tal y como refleja Julio Camba en La ciudad automática. ${ }^{8}$

Los escritores percibieron que el modelo de modernidad se había convertido en un producto de consumo, cuyo espacio estaba sometido a las leyes de oferta y demanda. Los vanguardistas son testigos directos de la transformación que adopta la ciudad a través de la competencia por la construcción de rascacielos cada vez más altos e innovadores. El centro de la Gran Ciudad, caracterizado por los rascacielos, los rápidos medios de transporte y los anuncios luminosos, chocaba de lleno con los barrios periféricos. Esta situación lleva a una aparente contradicción; mientras la ciencia, la tecnología y la economía viven un momento de esplendor, las estructuras sociales continúan estancadas y la desigualdad es cada vez más acuciante (Alarcón 2015: 11). La desestructuración aumenta progresivamente lo que lleva a un nuevo sistema urbano y un comportamiento que resulta caótico en el intento de adaptación del escritor visitante, como le sucede a Julio Camba:

¿Qué cosa extraña es esta que me ocurre a mí con Nueva York? Me paso la vida acechando la menor oportunidad para venir aquí, llego, y en el acto me siento poseído de una indignación terrible contra todo. Nueva York es una ciudad que me irrita, me irrita, naturalmente, muchísimo más todavía. Todas las comparaciones que se me ocurren para definir la clase de atracción que Nueva York ejerce sobre mí pertenecen por entero al género romántico: la vorágine, el abismo, el pecado, las mujeres fatales, las drogas malditas... ¿Será acaso Nueva York una ciudad romántica? (Camba 2015: 23)

Esta controversia urbana hizo que los escritores vanguardistas trabajasen y asentasen nuevos códigos lingüísticos y nuevas formas literarias para representar el espacio urbano. La ciudad evocada responde a una construcción subjetiva realizada sobre un espacio físico. En el caso de Camba, su visión no destaca por la descripción detallada y minuciosa del espacio urbano por el que transita, sino

\footnotetext{
${ }^{8}$ Esta perspectiva de Nueva York ha sido tratada por Juan Ramón Jiménez en las minificciones de Diario de un poeta reciencasado (1917). En el mismo momento en el que Camba publica los artículos recogidos en La ciudad automática (1932), se edita Jacinta la pelirroja de José Moreno Villa (1929) y García Lorca gesta Poeta en Nueva York (1929-1930), dos ejemplos de un gran número de poetas para los que la moderna ciudad influye de manera determinante en su obra. A pesar de que la poesía no es el género literario sobre el que se centra el análisis de este trabajo, resulta de interés tenerlo en cuenta a la hora de trazar el contexto en el que surge la obra de Camba. Para un análisis más extenso de la poesía de este periodo véase el trabajo de Julio Neira (2012).
} 
por la ideología que pretende transmitir a través de la misma, es decir, lo que busca es impactar al lector con los defectos o virtudes de la ciudad moderna. El proceso de construcción de la imagen poética es muy similar al que utilizan los poetas en este periodo, pudiendo definirse siguiendo la conceptualización que Guzmán Simón realiza para la lírica:

\begin{abstract}
... el espacio acaba por asumir una función sintáctica del texto que, de una manera u otra, proyecta en el sujeto poético cierto sentido metonímico. Dicha metonimia posee una función simbólica en la que se aprecia la valoración crítica del autor sobre la ciudad de Nueva York. Esta mirada describe la ciudad a través de la construcción de un espacio simbólico. (Simón 2014: 126)
\end{abstract}

Esta perspectiva crítico-descriptiva se observa en la presentación de la ciudad de Nueva York como una masa uniforme y mecanizada, frente al barrio periférico de Harlem o la judería de Rivington Street, conformando no solo dos perspectivas de observación con respecto al mismo espacio, sino también destacando la división social existente y la dicotomía centro/periferia tan característica de las ciudades metropolitanas. La imagen arquetípica de Nueva York se corresponde con el centro de la misma, caracterizado por los rascacielos y los anuncios luminosos por los que transita una masa anónima a gran velocidad economizando sus viajes y su tiempo. Sin embargo, la metrópolis neoyorquina tiene otra cara: las periferias que reflejan la crueldad de los espacios urbanos de base capitalista y las desigualdades sociales existentes en las perfectas y modernas ciudades del siglo $x x$.

A este hecho, se suman los problemas de identidad surgidos de la tecnología y del uso de la máquina a partir de los años 20 que proporcionaban velocidad a la vida diaria y anonimato. La ciudad se presenta como un espacio fragmentario e ilimitado en el que el tiempo tiene un precio y el ciudadano debe moverse constantemente y a mucha velocidad para economizarlo al máximo, lo que lleva a que los autores reflejen en sus novelas la ansiedad y la anonimia que les produce este nuevo lugar. Es precisamente la relación entre las percepciones y el ambiente lo que genera el caos de sentimientos, alegría y angustia, e imágenes recibidas y le otorga al texto un carácter subjetivo. De esta forma, la ciudad se convierte en un estado de ánimo difícilmente separable del ámbito psicológico, de lo social y de sus inquietudes intelectuales. Los autores sienten el impacto del progreso, de la tecnología y de la máquina, sensaciones que se reflejarán tanto en la forma como en el contenido del texto. Así, rompen definitivamente con el modo de narrar decimonónico e introducen técnicas cinematográficas. La ruptura del orden lógico discursivo puede interpretarse como una representación de la fragmentariedad y de la velocidad que perciben, buscando generar en el receptor un impacto similar al que la ciudad provoca en ellos. Sienten la constante necesidad de asimilar el fragmentarismo, la mecanización y la artificiosidad de la moderna ciudad mecanizada en la que destacan la estandarización y la producción en serie (Villanueva 2015: 199-237).

El espíritu cosmopolita de Nueva York enuncia la utopía del futuro donde el hombre se irá convirtiendo progresivamente en una especie de robot y la má- 
quina dominará por completo el espacio urbano. Al final de la novela se perciben características propias de la ciencia ficción, un género que comienza a desarrollarse en este periodo y que terminará por sustituir la utopía social durante el franquismo, como puede percibirse en el siguiente fragmento:

La mecánica nos manda. Somos esclavos de las máquinas y no podemos tener gustos contrarios a sus funciones. Y si esto se ve claro en alguna parte, es en Nueva York más que en ninguna otra. Ríanse ustedes de esa especie según la cual todo el mundo tiene aquí siempre mucha prisa. [...] De mí sé decir que yo no tengo jamás prisa ninguna, pero el hecho mecánico se nos impone aquí con tal fuerza, que yo no tomo nunca un tren local en el Subway cuando puedo tomar un expreso, así como, pudiendo hablar por teléfono con todo el mundo, no hablo ya directamente con casi nadie. Después de todo, amigo lector, yo soy un hombre moderno. Soy un hombre de mi época, aunque, la verdad, preferiría serlo de cualquier otra... (Camba 2015: 208-209)

2.4. Hacia la ciudad de vacaciones. La reconfirmación del planteamiento urbano utópico

La representación urbana utópica sufre una pausa durante la dictadura franquista. Sin embargo, las reformas sociales y urbanas llevadas a cabo durante la época del desarrollismo impulsan una nueva imagen de la misma a través de la ciudad de vacaciones, que se desarrollará a finales del siglo xx y que alcanzará su máximo esplendor narrativo durante los primeros años del siglo XxI. Esta nueva tipología urbana viene condicionada por el consumismo agresivo de los últimos tiempos. El ejemplo más claro lo constituye la imagen que ofrece Escargot de Marina d'Or en la novela El dorado. La ciudad de vacaciones es la meta del sueño turístico al que aspira la clase media. Marina d'Or aparece configurada como un no lugar (Augé 1993) en el que los turistas se mueven constantemente sin entablar relación entre ellos y siguiendo un mismo patrón de comportamiento. En relación con el no lugar, se encuentra la desaparición de los espacios exteriores (Ménedez Rubio 2012). Es decir, la vida cotidiana se desarrolla en el interior de los centros comerciales, de los balnearios de agua salada, de los hoteles... Esto produce que el turista únicamente transite el exterior para ir a la playa o para salir de alguna de las instalaciones e introducirse en otra por lo que la famosa Avenida Marina d'Or queda concebida como un mero lugar de tránsito. La desaparición del exterior se hace aún más notable durante el Encuentro Mundial de la Familia a través de los diferentes malls de la feria.

El concepto ciudad de vacaciones se corresponde con un nuevo espacio urbano relacionado con el ocio caracterizado por el sedentarismo. El turista ahora no va a ser el viajero que se mueve constantemente en busca de nuevas experiencias y aventuras, sino que será un ciudadano más de un espacio urbano. El asentamiento del turismo en un complejo fijo que ofrece todo lo necesario para el disfrute de las vacaciones tiene su antecedente en las periferias de las ciudades metropolitanas en las que se reservaban espacios de ocio y descanso para la población más selecta. Estos espacios se encuentran en relación con el primitivo suburbio estudiado por Mumford (2012: 803-875) en el que existían puntos con- 
cretos a los que se acudía con fines terapéuticos como los balnearios, generando el actual prototipo de turista. Para enmarcar conceptualmente la ciudad de vacaciones, se puede aplicar la definición que ofrece Louis Marin sobre Disneylandia:

\begin{abstract}
Así, Disneylandia es una utopía apresada por la ideología en cuanto que es la representación de la relación imaginaria que la clase dominante de la sociedad americana mantiene con sus condiciones reales de existencia y más precisamente con la historia real de los Estados Unidos y con el espacio exterior. Es la proyección fantástica de la historia de la nación americana en su doble instauración respecto de lo extraño y respecto del mundo natural, la metáfora desplazada de la representación ideológica. (Marin 1975: 264)
\end{abstract}

Los espacios turísticos conformados en este periodo son lugares jerarquizados en función de las clases y de los grupos sociales a los que se asocia la construcción de las nuevas edificaciones, puesto que su finalidad es ofrecer un producto al consumidor que sea capaz de adquirir durante un corto periodo de tiempo. La ciudad de vacaciones simboliza precisamente lo que el trabajador no puede tener durante el resto del año. De esta forma, se puede definir como una utopía, a pesar de que se ha materializado, porque el turista proyecta sobre este espacio físico fantasías y anhelos distintos a los habituales y desarrolla dentro de ella un comportamiento diferente al cotidiano. Aunque es un espacio utópico llevado a la práctica, no deja de ser un universo paralelo al habitual, un sueño que se hace realidad durante un corto espacio de tiempo, en definitiva, una especie de Barataria quijotesca.

La ciudad de vacaciones creada en la década de los 50-60 es un componente clave de la sociedad de consumo y un elemento diferenciador entre comunidades y grupos sociales más acomodados. No deja de ser una marca más de las grandes desigualdades sociales, no solo por el determinado poder adquisitivo del turista, sino por la organización de las mismas. La característica de todas ellas es la de diseñarse como un producto de ocio en base al sol y a la playa, elementos naturales que también pueden ser consumidos a través de las diferentes actividades. Al consumir y disfrutar dentro del espacio turístico, el turista se siente alejado de la cotidianidad laboral y goza de una vida y de un espacio urbano que anhela, a la vez que pretende demostrar que posee cierto estatus económico o un determinado gusto cultural (Antón 1998: 20). Esta conceptualización espacial es la observada en la configuración de Marina d'Or a través de Escargot:

El tema es que todos estos elementos [...], todo está articulado por un laberinto de pasillos empedrados que llevan de una pequeña plazoleta a otra y de esta a un nuevo espacio de recreo y descanso con más sillas de plástico. Justo en el centro, de espaldas al mar, junto a una carpa puntiaguda de color naranja y perforado por nuevos surtidores de agua y hasta cataratas chisporroteantes, un macizo rocoso de fibra de vidrio al que no paran de encaramarse los paseantes en busca de una mejor vista y a la caza de esa experiencia exótica con la que tienen previsto pertrechar sus vacaciones. (Cantavella 2008: 18) 
La proyección ideológica produce en el visitante una representación de la vida cotidiana, mezclando lo extraño y lo familiar y otorgándole la mayor comodidad, confort y bienestar posibles, sin dejar de lado el consumo. El progreso técnico y científico está muy presente en estos paraísos vacacionales, representados bajo la imagen del orden y de la legalidad, tal y como constantemente defenderá el relaciones públicas de Marina d'Or, debido a que sus instalaciones poseen el mayor balneario de agua marina de Europa. Los efectos ideológicos que el espacio ejerce sobre el habitante se van a descubrir al mismo tiempo que este realiza el itinerario correspondiente para conocer todos y cada uno de los rincones de la ciudad. De esta forma, como lectores, conocemos Marina d'Or a través de Escargot, quien nos describe cómo sobreactúan los turistas, el rol que adquieren voluntariamente y cómo se organizan y distribuyen las relaciones sociales entre ellos dependiendo de su capital económico y del espacio que habiten en la ciudad, regido por el número de estrellas que posee cada hotel. Escargot se convierte en el narrador de todo un ceremonial que va desde los orígenes hasta la actualidad de Marina d'Or. A este respecto, cabe destacar la "objetividad" con la que se presenta, puesto que el protagonista no entra dentro de la dinámica al negarse a imitar estos comportamientos. De ahí que continuamente muestre su inconformismo y su inadaptabilidad a la hora de formar parte del grupo.

Resulta de especial relevancia la entrada del complejo que constituye un límite intermedio entre el espacio utópico y el mundo real. En el momento en el que el turista la atraviesa, efectúa una operación de cambio o sustitución de modas y comportamientos, adoptando el papel que la ciudad le exige, un comportamiento similar al que realiza el náufrago que llega a una isla utópica. La adaptación es la única forma que tiene de participar activamente dentro de ella. La entrada supone la inmersión en Marina d'Or, por tanto, el mundo exterior o real queda neutralizado por el utópico y el turista se olvida durante un tiempo de su vida cotidiana. Ahora no es un trabajador que vive inmerso en la rutina diaria, sino que forma parte del ideal de la clase media. Su única tarea aquí es consumir y disfrutar del ocio y de la tranquilidad del complejo vacacional. Así se refleja en la entrada triunfal que realiza el turista que es capaz de alcanzar el paraíso y gozar de él durante unos días.

En términos generales, Escargot ve a los turistas como una sociedad trivial que necesita realizar rituales de convivencia y de identificación con respecto a otros grupos, conocidos como "Marinemas". ${ }^{9}$ Esta forma de analizar el turismo es la que defiende el antropólogo Nelson H. H. Graburn (Antón 1988: 19) quien sostiene que es una manifestación de la necesidad que tienen los humanos para recrearse y jugar. Por tanto, es el ritual que las sociedades contemporáneas utilizan para ello, de la misma forma que las primitivas se valían de rituales sagrados. La manera en la que cada turista ocupa su tiempo libre le identifica de forma individual con respecto al resto y en su forma de relacionarse con los demás.

\footnotetext{
9 "Desde un punto de vista estructuralista es posible aislar una serie finita de marinemas, unidades mínimas de significado que por sí solas podrían explicar el sentido último de la ciudad de vacaciones Marina d'Or así como describir sus pautas de comportamiento" (Cantavella 2008: 70).
} 
La utopía levantina se presenta bajo una organización espacial racional al mostrar una imagen de pureza y neutralidad que esconde la ideología capitalista, basada en el orden social y en las desigualdades que generan las riquezas. El espacio se distribuye conforme al poder adquisitivo de cada turista y se dirige siempre al consumo, tanto de ocio como de otro tipo de productos (cosmética, recuerdos, ropa, complementos...), todo ello sin salir de la ciudad de vacaciones. De esta forma, el espacio simbolizado tiende a la abstracción y homogeneización a través de la imagen, concretamente de la publicidad, por lo que el turista tiende a la confusión entre realidad y ficción. Por este motivo, Escargot no se encuentra cómodo en Marina d'Or y se muestra como un extraño. Ve la ciudad de vacaciones como una creación ficticia que se convierte en una falsa utopía, cuya última finalidad es que el turista consuma sin cesar durante su periodo de vacaciones.

\section{CONCLUSIÓN: HACIA LA UTOPÍA DEL SIGLO XXI}

El concepto de utopía está intrínsecamente relacionado con el de ciudad. A través de los modelos seleccionados, los autores presentan proyectos urbanos ideales y perfectos que ofrecen a sus habitantes una vida semejante a la del Paraíso bíblico, otro modelo utópico. Así mismo, la ciudad utópica desarrollada en la narrativa española se relaciona no solo con el descubrimiento de América, sino también con los modelos planteados en época clásica que fueron llevados durante la Edad Media y los siglos de Oro a las islas, al tiempo que las convierten en el espacio utópico por excelencia. A partir del siglo xVIII y sobre todo durante el XIX, la isla deja paso al espacio urbano que aparece configurado como un reducto aislado dentro de la geografía del propio país, tal y como se observa en La Nueva Utopía de Ricardo Mella.

En la obra de Mella se percibe un cambio fundamental con respecto a las anteriores utopías. Si en Barataria y Sinapia se buscaba la felicidad a través del bienestar económico, la igualdad social y la justicia, tanto en la ciudad de Mella como en la de Camba, la felicidad se halla a través del progreso y de la mecanización, puesto que liberan al trabajador y le proporcionan mayor descanso, confort y facilidad a la hora de desempeñar su trabajo. Debido a la influencia del socialismo, del anarquismo y del comunismo, las utopías sociales desarrolladas hasta 1936 seguirán este camino. Tras el periodo de lapso durante el franquismo en favor de la ciencia ficción, el modelo utópico que se retomará, en clara relación con el desarrollismo y las políticas neoliberales de la Transición, será el de la ciudad de vacaciones entendida como el sueño al que todo trabajador, ahora perteneciente a la clase media, aspira.

La ciudad de vacaciones supone no solo el triunfo del consumismo y de las políticas neoliberales que traen consigo la especulación con el espacio urbano y la transformación de las ciudades costeras para ofertar productos vacacionales, sino también un nuevo modelo que se basa en ofrecer al trabajador los lujos, el confort y el descanso de los que no puede disfrutar en su día a día. Esto trae consigo la formación del turismo de masas y la adopción de un rol para adaptarse a las exigencias, una interpretación reflejada de forma irónica 
en El Dorado. Ahora, el turismo de masas y la especulación deberán adaptarse a los nuevos modelos urbanos y al nuevo turismo que se pretende fomentar: un turismo sostenible en sintonía con el medio ambiente. Ofrece respeto por la naturaleza y se compromete a no destrozar los parques naturales ni a engullir las formas de vida de la comunidad que van a transformar. Este modelo ya aparece enunciado en la obra de Cantavella como una ampliación de Marina d'Or y como la nueva utopía del siglo xxI:

RP: Lovely, simply lovely...aunque déjame que te diga que Marina d'Or Golf es un ejemplo paradigmático de desarrollo turístico sostenible, un montaje absolutamente compatible con el medio ambiente de la zona donde vamos a construir. Ten en cuenta que de los dieciocho millones de metros cuadrados sobre los que se actuará, más de nueve millones serán zonas verdes, no te digo más... y de la otra mitad, todavía dedicaremos otro millón o millón y medio de metros cuadrados a magníficos jardines como el que ya has visto... veo que las cifras te han dejado mudo. (Cantavella 2008: 137)

\section{OBRAS CITADAS}

Alarcón Sierra, Rafael (2015): "Llámalo sueño: Nueva York en la narrativa española", Ínsula. Revista de Letras y Ciencias Humanas, n. ${ }^{\circ} 821$, pp. 11-16.

Antón Clavé, Salvador (1998): "La urbanización turística. De la conquista del viaje a la reestructuración de la ciudad turística", Documents d'analisi geográfica, n. ${ }^{\circ}$ 32, pp. 17-43.

Anónimo (1976): Sinapia. Una utopía española del Siglo de las Luces. Ed. Miguel Avilés Fernández. Madrid, Editora Nacional.

Augé, Marc (1993): Los "no lugares". Espacios del anonimato. Una antropología de la sobremodernidad. Barcelona, Gedisa.

Avilés Fernández, Miguel (1981): "El sueño de Juan Maldonado". En: Sueños ficticios y lucha ideológica en el Siglo de Oro. Madrid, Biblioteca de visionarios y heterodoxos, pp. 107-179.

_ (1982): "Utopías españolas en la Edad Moderna", Chronica Nova, n. 13, pp. 27-51.

Calvo Carilla, José Luis (2008): El sueño sostenible. Estudios sobre la utopía literaria en España. Madrid, Marcial Pons.

Camba, Julio (2015): La ciudad automática. Ed. José Luis García Martín. Sevilla, Renacimiento.

Cantavella, Robert Juan (2008): El Dorado. Barcelona, Random House Mondadori.

Cervantes, Miguel de (1996): Don Quijote de la Mancha. Madrid, Alba Libros.

Cro, Stelio (2005): "La utopía de las dos orillas (1453-1793)", Cuadernos para investigación de la literatura hispánica, n. ${ }^{\circ} 30$, pp. 15-268.

Dubois, Claude (1968): Problémes de l'utopie. París, Lettres Modernes.

Eliav-Feldon, Miriam (1982): Realistic Utopias: Ideal Imaginary Societies of the Renaissance, 1516-1630. Gloucestershire, Clarendon Press.

Facuse, Marisol (2010). "La utopía y sus figuras en el imaginario social", Sociológica, vol. xxv, n. ${ }^{\circ} 72$, pp. 201-213. 
Gómez Redondo, Fernando (1982): "Tomás Moro en el ámbito hispánico", Cuadernos Hispanoamericanos, vol. CCCLXXXV, n. ${ }^{\circ}$ 7, pp. 214-221.

Guzmán Simón, Fernando (2014): “Del reconocimiento a la reescritura de Nueva York y la poesía española", Campo de Agramante: revista de literatura, n. ${ }^{\circ} 20$, pp. 123-136.

Janoschka, Michel (2011): "Geografías urbanas en la era del neoliberalismo. Una conceptualización de la resistencia local a través de la participación y la ciudadanía urbana", Investigaciones geográficas. Boletín del Instituto de Geografía, n. ${ }^{\circ}$ 76, pp. 118-132.

Janoschka, Michel; Sequera, Jorge (2014): "Procesos de gentrificación y desplazamiento en América Latina - una perspectiva comparativista". En Juan José Michelini (ed.): Desafíos metropolitanos. Un diálogo entre Europa y América Latina. Madrid, Catarata, pp. 82-104.

Lapouge, Gilles (1975): Utopie et civilisation. Génova, Weber.

López Estrada, Francisco (1981): "Por los caminos medievales hacia la utopía: Libro de los Ejemplos, núm. 6". En: Aspetti e problema delle Letterature Iberiche. Studi offert a Franco Meregalli. Roma, Bulzoni, pp. 209-217.

Mannheim, Karl (1966): "La mentalidad utópica". En: Ideología y utopía. Introducción a la sociología del conocimiento. Madrid, Aguilar, pp. 260-341.

Manuel, Frank E. (1971): French Utopias. An anthology of ideal societies. Nueva York, Shocken Books.

Marin, Louis (1975): "Degeneración utópica: Disneylandia". En: Utópicas. Juegos de espacios. Madrid, Siglo XXI, pp. 263-288.

Martínez García, José Carlos (2006): "Un catálogo de utopías de la llustración española", Cuadernos de llustración y Romanticismo, n. 14, pp. 257-269.

Mella, Ricardo (1890): La Nueva Utopía, https://www.ricardomella.org/utopia.html [última consulta: 12.04.2019].

Méndez Rubio, Antonio (2012): La desaparición del exterior. Cultura, crisis y fascismo de baja intensidad. Zaragoza, Eclipsado.

Mumford, Lewis (2012): "Suburbios... y más allá". En: La ciudad en la historia. Sus orígenes, transformaciones y perspectivas. Logroño, Pepitas de Calabaza, pp. 803-875.

- (2013): Historia de las utopías. Logroño, Pepitas de Calabaza.

Neira, Julio (2012): La historia poética de Nueva York en la España contemporánea. Madrid, Cátedra.

Núñez Lavedeza, Luis (1976): Utopía y realidad. La ciencia ficción en España. Madrid, Ediciones del Centro.

Ortega y Gasset, José (1993): El tema de nuestro tiempo. Madrid, Espasa-Calpe.

Santos, Antonio (2008): Barataria, la imaginada. El ideal utópico de don Quijote y Sancho. Navarra, Centro de Estudios Cervantinos y Universidad de Cantabria.

Sargent, Lyman Tower (2001): "Utopianism and National Identity", Critical Review of International Social and Political Philosophy, vol. III, n. ${ }^{\circ} 2-3$, pp. 87-106.

Servier, Jean (1969): Historia de la utopía. Venezuela, Monte Ávila Editores.

Villanueva, Darío (2015): "Poeta en Nueva York desde el expresionismo de 'La aurora'". En: Imágenes de la ciudad. Poesía y cine, de Whitman a Lorca. Madrid, Cátedra, pp. 199-237. 